or even entirely, due to the pressure of the enlarged pregnant uterus. The septum was incised with a knife between two "pains," the incision was then enlarged with a finger tearing it through, the "waters" were rnptured, and the child very shortly after was delivered quite easily and naturally.

Remarks.-Cases of transverse septum of the vagina are distinctly rare, and when leading to urethral coitus, and later impeding labour, they become still more rare. Vaginal septa are either transverse or vertical, but only the former will be'considered now. Transverse vaginal septa are either congenital or acquired-i.e., inflammatory in origin. The one now described was evidently congenital, for though she had had scarlet fever there was no history of genital inflammation.

Dr. C. J. Cullingworth ${ }^{1}$ has recorded two cases of transverse vaginal septa. The first case, that of a widow, aged 38 years, was due to an attack of "irflammation at the age of 12 of the genital organs." There was an opening in the "thin and flexible septum" large enough to admit a uterire sound. Though she had been married nearly six years she was never pregnant and was " not aware of any difficulty or inconvenience in her marital relations." In the second case the septum obstructed labour; it was evidently a congenital case. There was always slight leucorrboea, and pain at the periods was "excessive" during the previous three years on the first day only of the flow. Under ether an opening of the size of the urethra was found in the septum, this was dilated and torn through, delivery soon following.

Dr. Cullingworth remarks that probably in all cases of transverse vaginal septa there is an opening, though often very small, and these small openings show how very enterprising the spermatozoa are. Further, he says that, "as in many other forms of vaginal abnormality, the urethra is of $t$ n four d much larger than usual"; possibly in his case also coitus had taken place per uretbram. In atresia hymenalis it was pointed out by Oldbam that the urethral orifice is more patulous than it is normally. Dr. C. R. Prance ${ }^{2}$ records two cases of transverse vaginal septa. Neither of the patients were pregnant; the first was unmarried and the second was married but was sterile; she soon became pregnant after the opening in the septum- of the size of a pin-hole only-was enlarged and the septum was destroyed. Dr. Gervis ${ }^{3}$ also narrates a case. The patient was a woman, aged 22 years. There was an annular hymen which was fairly defined, so that the septum was not a misplaced hymen. She had corstant leucorrboa in the intervals of her menstrual periods. A small probe only conld be passed through the hole in the septum, which was very thin. "Whetber it was congenital or due to early adhesive inflammation it was difficult to decide." Dr. Cullingworth ${ }^{4}$ in his paper says that the septum usually consists of "a thin, not very vascular, and easily lacerable membrane." Dr. R. S. Fancourt Barnes gives a case of a primipara, aged 21 years, where a "thick septum at least two inches in thickness existed." There was a small hole which admitted a nterine sound when some pressure was exerted in its introduction. The septum impeded labour.

Theše cases of vaginal septa are quite distinct from cases of cicatricial contraction or occlusion of the vagina. These latter have led to Cæsarean section to remove the child when the vagina has been so obliterated as to prevent birth per vaginam. Such a case was narrated by Stande in a paper on Cicatricial Contractions of the Vagina Impeding Labour. It led to an interesting discussion of the subject and its etiology. ${ }^{6}$ Dr. Galabin bas recorded a similar case. ${ }^{7}$

Concerning the dilated condition of the urethra, the result of admitted urethral coitus, most of the recorded cases of the latter have been in instances of absent vagina. In THE LANCET ${ }^{8}$ of 1869 it is mentioned that Dr. T. A. Emmet in his book on "Vesico-Vaginal Fistula" (1868) records two cases of coitus per urethram. In both cases the uterus and vagina were absent. The urine was easily retained in spite of the dilated urethra, "which was so patulous that the index finger could be introduced without difficulty" in one of the cases, while "in connexion the bladder bad been

1 THE LANCET, April 13th, 1889, p. 726

2 Tre

8 Transactions of the Obstetrical Society of London, vol. xxiv., p. 210. 4 Loc. cit.

5 Transactions of the Obstetrical Society of London, vol, xxr., p. 99. ${ }^{6}$ Brit. Med. Jour., Ep'tome, July 1st, 1893.

7 Transactions of the Obstetrical Society of London, vol. xviii., p. 252. 8 TAE LANCET, Feb. 20th, 1869, p. 260 entered without either party being aware of the malformation." Dr. J. O. Gooding ${ }^{9}$ records a case in which the lower portion of the vagina was undeveloped. The retained menses had burst throngh the urethra. The bladder could be entered with the greatest ease, even with two fingers, and this digital examination of the bladder was painless. There was no incontinence of urine. The patient was married and coitus was followed by immediate desire to micturate. Professor Langenbeck 10 recorded the following case. The patient was 23 years of age; menstruation began at the age of 14 years and the discharge took place per urethram. She bad been married for three years. "Coitus was effected by the urethra." The vagina was entirely absent and the uterus was rudimentary.

In the case the subject of this paper the vagina was not absent, and it subsequently fulfilled its function as the parturient passage, but the transverse septum in it prevented its proper use in coition and led to the urethra becoming used and consequently dilated. There can be no doubt that previously to, and just after, marriage there was an opening in the septum by which the menses escaped and by which eventually the spermatozoa were able to reach the uterus. That the patient became pregnant must bave been due to intercourse having occurred per vaginam. Subsequently to impregnation on an occasion of forcible coitus, perbaps even the identical occasion of her impregnation, the opening in the transverse vaginal septum must bave been torn; its edges thus freshered wonld be approximated by the collapse of the vaginal walls; this tear then evidently eventually healed up, so that at the time of labour no opening on examination conld be detected. Thus the upper part of the vagina and the already im regnated uterus became completely shut off. Urethral coitus must have followed as a result of this practical occlusion of the vagina, which probably became more and more marked as towards the latter balf of the pregnancy the increasing size and wejght of the foetus and uterus helped to force and bulge down the vaginal septum and thus entirely obliterate the vagina for practical purposes. So patulous bad the urethra become that the index finger pass $\epsilon d$ quite easily and painlessly into the bladder.

Leyton, N.E.

\section{AN OBSCURE AND COMPLICATED CASE OF CARCINOMA OF THE STOMACH.}

\section{BY CHARLES FRANCIS STEELE, L.R.C.P. LOND., M.R.C.S. ENG.}

CAsEs of carcinoma of the stomach, which are more or less atypical, are not uncommon. but it is, I think, rare to find practically none of the cardinal symptoms present, as in the case which I am about to describe, especially when the disease is well advanced. The patient was seen during his last illness, to my knowledge, by seven medical men, yetand I think not unnaturally so-the real state of affairs was not diagnosed, or indeed suspected, until the day before his death. In addition to the obscurity of its diagnosis the case presented interesting complications.

A well-to-do man, aged 46 years, consulted my father, Dr. Oharles Steele, for the first. time on August 1st, 1500, complaining of debility and depression, also of pain in the lower right chest and behind the lower right ribs, which was aggravated by gentle pressure. The hepatic region was tender in front, but the liver itself was not enlarged. The tongue was coated with a yellowish fur. "Rbeumatic" pains in the shoulders, the upper arms, and the pectoral regions were complained of. His general condition was a good deal relieved by saline aperients and rest in bed, and on August 12 th be was able to sit up and take food, which he much relished. It was suggested that when he became stronger a "course" at Droitwich might prove beneficial. In consequence of this remark the patient, a self-willed man, insisted upon going forthwith to Droitwich, and he went there on August 16th. The reports from his medical adviser there were not encouraging; the weakness progressed steadily, and after a stay of 18 days he was prevailed upon to return to his home. At Droitwich, by reason of the 
marked and increasing weakness, and also the presence of several fawn-coloured patches on the right chest in front and on the back and legs, his malady was diagnosed as Addison's disease. No nausea or vomiting was complained of.

It was at this stage (on Sept. 4th) that the case came under my care, Dr. Steele being away on his holiday. I found the patient in bed, lying on his back. He had apparently stood the journey well. He was of slight build, of dark complexion, and of somewhat anxious expression. The sclerotics were slightly jaundiced, the mucous membranes were markedly anæmic, and the tongue was coated with white fur. During my examination he complained bitterly of pain in the back and chest when turning on his side or when sitting up. On looking at the coloured patches I concluded that those on the legs, being scaly, were due to an old psoriasis of which there was a history; the other patches on the chest and back were caused by the microsporon furfur and faded without treatment. Over the lower right ribs was a distinct bulging, the intercostal spaces being obliterated. The bulging was of about the size and the shape of a small inverted saucer, and it was bisected by the anterior axillary line. Pressure over this area caused considerable pain, which was most intense at one particalar spot. On percussing over this bulging the note was deficient in resonance and a distinct thril was felt. With this exception nothing abnormal was found in the chest. There was no cough. The heart sounds were normal. The pulse, which was full, was regular and of high tension; it was 120, and at no time did it fall below this until his death. The temperature was $100.2^{\circ} \mathrm{F}$. and it oscillated slightly above and below this, being at its highest at night. The urine was normal in appearance and there was no albumin or sugar. The bowels were confined. The limb muscles were Habby and wasted. There was no nausea or pain after food. As Dr. Steele also had found, the abdominal muscles were held so rigidly contracted and pressure caused so much discomfort that a satisfactory examination of the abdomen could not be made, but no growth was felt. I concluded that a cyst, which was possibly hydatid but also conceivably of a cysto-sarcomatous or simple nature, was present either in the upper and anterior part of the right lobe of the liver or else between this and the diaphragm. On the following morning in consultation an exploring-needle was thrust into the bulged area and about a drachm of clear pale yellow fluid was withdrawn. An exploratory incision was advised with drainage of the cyst, should such be found, but to this the relatives would not consent. The treatment was therefore purely symptomatic: pain was greatly relieved by morphine and the bowels were kept active by soapy water and turpentine enemata. The swelling appreciably diminished in size, but the wasting and prostration still continued.

On Sept. 16th Dr. R. Shingleton Smith, physician to the Bristol Royal Infirmary, saw the patient with me. At his stage he was in a very critical condition, being intensely anæmic, prostrate, and quite helpless. He lay continuously on his back, apathetic, and listless, and he still complained greatly of pain when he was shifted on to either side or when he was held sitting up in bed. Neither at this time nor during his illness was there any nausea or vomiting, and his food-broths, meat essences, milk, \&c. - was well taken and retained. The abdominal muscles were so wasted and the general debility was so great that a much more thorough examination of the abdominal viscera was possible than had been the case heretofore. On pressing deeply beneath the left costal margin two hard lumps of the size of walnuts were to be felt placed side by side but separated by a small interval. A diagnosis of carcinoma of the stomach was made and a hopeless prognosis was given.

In answer to leading questions bearing on the diagnosis the following points in the past history were brought to light. Two years previously a medical man had been consulted, the patient being away from home for change of air, and he had stated that there was a "growth beneath the heart," and on the patient expressing doubt the medical man had exclaimed: "I can feel it as distinctly as I can feel the watch in my waistcoat pocket." It does not appear, however, that he expressed any opinion as to the nature of the growth or mentioned the stomach in connexion therewith. Six months later a quantity of "corruption" was brought up. The medical adviser then consulted considered that the patient had been poisoned, but nothing of this sort ever recurred. Six months later bleeding from the anus occurred, evidently due to piles, which were operated upon, and the bleeding ceased forthwith. There was no history whatever of any nausea or vomiting or pain in the epigastrium, though he had at times complained of uneasiness after food. Only within three months of death had there been any weakness or wasting.

At the necropsy, which I made on the afternoon of Sept. 17th, death having taken place at 6 A.M. on that morning, I found the liver very adherent to the parietes excepting over the area corresponding to the bulging on the surface. Why there should have been so much pain and swelling in this region I do not pretend to know, but I can only suppose that an "adhesion cyst" existed which had been induced to absorb by the drachm or so of fluid withdrawn by the exploring needle The liver was not enlarged and showed nothing abnormal beyond a thickened capsule. The stomach was not adherent or dilated and the entire length of the lesser curvature was felt to be occupied by a hard mass. The stomach, after ligature, was removed and opened. The contents, three or four ounces, consisted of a pale yellow, thickish fluid. There was no blood. The cancerous mass measured four inches long by two and a half inches wide and it was about one inch in thickness ; the pylorus itself was not involved. On the mucous surface of the growth was a large shallow ulcer, measuring two and a half inches by one inch. The edges were blunted and only slightly raised, the floor was ragged, and there was no fresh blood upon the ulcer. The specimen was placed in spirit; it is now in the museum of the Bristol Royal Infirmary. Scattered throughout the great omentum were nodules of growth varying in size from a small pea to a filbert. The pancreas was adherent to the spine, a little enlarged and indurated. The spleen was not enlarged The kidneys and suprarenal capsules were normal. No other growth was felt. The thoracic cavity was not examined.

The case is remarkable for two reasons: (1) the condition of the liver, where so little mischief gave rise to so much pain and bulging on the surface ; and (2) because, although there was such extensive disease of the stomach, there were so few symptoms to indicate it. It is in those cases where the growth is on the posterior wall of the stomach and does not involve the pylorus that carcinoma is likely to be overlooked. My father informs me that, in his experience, the pain and stiffness on movement, which were so marked in this case, not uncommonly point to malignant disease of, or in close proximity to, the spinal column.

Clifton.

\section{AN INSTANCE OF EXCESSIVE ENTERIC RASH IN CHILDHOOD.}

\section{By ARTHUR MAUDE, L.R.C.P. LOND., M.R.O.S. ENG.}

THE accompanying illustration gives a picture of the plenitude of the rash in a case of enteric fever. The patient was an ill-nourished boy, aged 12 years. The rash first appeared on the tenth day and it reached its greatest development five days after. The spots were then so numerous that an attempt to count them absolutely failed, and a comparison with the excellent plate in Murchison's book showed far more than two spots to one. They numbered certainly many hundreds ; they were crowded over the abdomen and the chest, they were numerous on the back, the arms, the thighs, and the neck; they occurred on the cheeks and forehead, and they even invaded the margin of the mucous membrane of the lips. This great intensity of rash lasted from about two to three days and was followed by fresh crops of a few spots for several days more. The spots were typical in every way, though a few were of unusually large size and of unusually irregular oval outline. The type of disease was serere and at the height of the rash the child was extremely ill. The rash was beginning to fade when the photograph was taken. Dr. J. S. Tew, the medical officer of health of the West Kent Combined Districts, kindly examined by the Widal reaction for me at the height of the rash. He found marked clumping action with 1 to 40, but the agglutination was not specially rapid, nor 